\title{
Reacting the Unreactive: A Toolbox of Low-Temperature Solution-Mediated Reactions for the Facile Interconversion of Nanocrystalline Intermetallic Compounds
}

\author{
Robert E. Cable and Raymond E. Schaak* \\ Department of Chemistry, Texas A\&M University, College Station, TX 77842-3012
}

\section{Experimental Details}

Materials. The following metal reagents were used: $\mathrm{Cu}\left(\mathrm{C}_{2} \mathrm{H}_{3} \mathrm{O}_{2}\right)_{2} \cdot \mathrm{H}_{2} \mathrm{O}(98.0-102.0 \%)$, $\mathrm{HAuCl}_{4} \cdot 3 \mathrm{H}_{2} \mathrm{O}$ (99.99\%), $\mathrm{K}_{2} \mathrm{PtCl}_{6}$ (40.11\% Pt), and $\mathrm{SnCl}_{2}$ (anhydrous, $99 \%$ min.). The reducing agent (for the synthesis of the initial reagent), surface stabilizer, and solvent were $\mathrm{NaBH}_{4}(98 \%)$, poly(vinyl pyrrolidone) (PVP, MW = 40000 or MW = 630 000), and tetraethylene glycol (TEG, $99+\%)$, respectively. All chemicals were purchased from Alfa Aesar and used as received.

Reagent Synthesis. The nanocrystalline intermetallic powders were synthesized by a modified polyol process, which has been previously reported., ${ }^{1,2}$ An example synthesis of PtSn involved the sequential dissolving of $1.0500 \mathrm{~g}$ PVP ( $\mathrm{MW}=40000$ ) and $0.125 \mathrm{~g} \mathrm{~K}_{2} \mathrm{PtCl}_{6}$ in $150.0 \mathrm{~mL}$ of TEG by sonication and magnetic stirring. $\mathrm{SnCl}_{2}(0.1052 \mathrm{~g})$ was then dissolved by the same means. After the solution was vigorously stirred at room temperature under bubbling Ar for at least 1 hour, $45 \mathrm{mg}$ of $\mathrm{NaBH}_{4}$ freshly dissolved in $5 \mathrm{~mL}$ TEG was added slowly. Upon reduction, the solution turned a dark brown/black color, and was then heated to $245^{\circ} \mathrm{C}$ and turns dark black. The solution is then removed from heat and allowed to cool under bubbling Ar.

AuCu was synthesized by dissolving $6.9 \mathrm{mg} \mathrm{Cu}\left(\mathrm{C}_{2} \mathrm{H}_{3} \mathrm{O}_{2}\right)_{2} \cdot \mathrm{H}_{2} \mathrm{O}$ in $40 \mathrm{~mL}$ of TEG by sonication and magnetic stirring, followed by $13.5 \mathrm{mg} \mathrm{HAuCl} \mathrm{H}_{4} \cdot 3 \mathrm{H}_{2} \mathrm{O}$ and $103 \mathrm{mg} \mathrm{PVP}(\mathrm{MW}=$ 630 000). The solution was vigorously stirred at room temperature under bubbling Ar for 30 min, then reduced by the slow addition of $20 \mathrm{~mL}$ of a freshly prepared $12.5 \mathrm{mM}$ solution of $\mathrm{NaBH}_{4}$ in TEG. The reduced solution was heated to $315{ }^{\circ} \mathrm{C}$, removed from heat and allowed to cool under bubbling Ar. Powders were precipitated from solution by centrifugation and were washed thoroughly with ethanol.

Interconversion Synthesis. $\mathrm{Pt}_{3} \mathrm{Sn}$ was synthesized by first dispersing $10.7 \mathrm{mg}$ of $\mathrm{PtSn}$ intermetallic powder in $20 \mathrm{~mL}$ TEG by sonication and magnetic stirring. After the dispersion was vigorously stirred at room temperature under bubbling Ar for at least 1 hour, it was heated to $125{ }^{\circ} \mathrm{C}$, at which temperature $6.820 \mathrm{~mL}$ of a $10.0 \mathrm{mM}$ solution of $\mathrm{K}_{2} \mathrm{PtCl}_{6}$ in TEG was slowly added. The dispersion was slowly heated to $260^{\circ} \mathrm{C}$ and held at that temperature for $15 \mathrm{~min}$, then removed from heat and allowed to cool under bubbling Ar. This $\mathrm{Pt}_{3} \mathrm{Sn}$ product was converted back to PtSn by the same method outlined above, dispersing $4.9 \mathrm{mg} \mathrm{Pt}_{3} \mathrm{Sn}$ powder in $20 \mathrm{~mL}$ TEG, stirring under Ar for 1 hour, heating to $120^{\circ} \mathrm{C}$, slowly adding a solution of $4.1 \mathrm{mg}$ [3 
molar equivalents] $\mathrm{SnCl}_{2}$ in $2 \mathrm{~mL}$ TEG, and heating to $260{ }^{\circ} \mathrm{C}$ and holding for $30 \mathrm{~min}$. The conversion of PtSn to $\mathrm{PtSn}_{2}$ and back to PtSn was achieved by using this same method, with the following exceptions: $\mathrm{PtSn}_{2}$ was synthesized from PtSn by reacting 3 molar equivalents of $\mathrm{Sn}^{2+}$ at $275-280{ }^{\circ} \mathrm{C}$ for $30 \mathrm{~min}$. The $\mathrm{PtSn}_{2}$ was converted back to PtSn by reacting with 1.5 molar equivalents of $\mathrm{Pt}^{4+}$ at $255^{\circ} \mathrm{C}$ for 2 hours.

$\mathrm{AuCu}$ was converted to $\mathrm{AuCu}_{3}$ by first dispersing $2.2 \mathrm{mg} \mathrm{AuCu}$ in $15 \mathrm{~mL}$ TEG by sonication and magnetic stirring. After the dispersion was vigorously stirred at room temperature under bubbling Ar for 1 hour, it was heated to $125{ }^{\circ} \mathrm{C}$ and 3 molar equivalents of $\mathrm{Cu}\left(\mathrm{C}_{2} \mathrm{H}_{3} \mathrm{O}_{2}\right)_{2} \cdot \mathrm{H}_{2} \mathrm{O}$ in $2 \mathrm{~mL}$ TEG was added. The dispersion was slowly heated to reflux and held for $40 \mathrm{~min}$, then removed from heat and allowed to cool under bubbling Ar. Powders were precipitated from solution by centrifugation and were washed thoroughly with ethanol.

Characterization. Powder X-ray diffraction (XRD) data were collected on a Bruker GADDS three-circle X-ray diffractometer using $\mathrm{Cu} \mathrm{K} \alpha$ radiation. Transmission electron microscopy (TEM) images, selected area electron diffraction (SAED) patterns, and energydispersive X-ray analysis (EDS) were collected using a JEOL JEM-2010 TEM. Samples were prepared by sonicating the nanocrystalline intermetallic powders in ethanol and dropping a small volume onto a carbon-coated nickel or copper grid.

1. Cable, R. E.; Schaak, R. E. Chem. Mater. 2005, 17, 6835-6841.

2. Sra, A. K.; Ewers, T. D.; Schaak, R. E. Chem. Mater. 2005, 17, 758-766.

\section{Additional XRD and TEM Data}

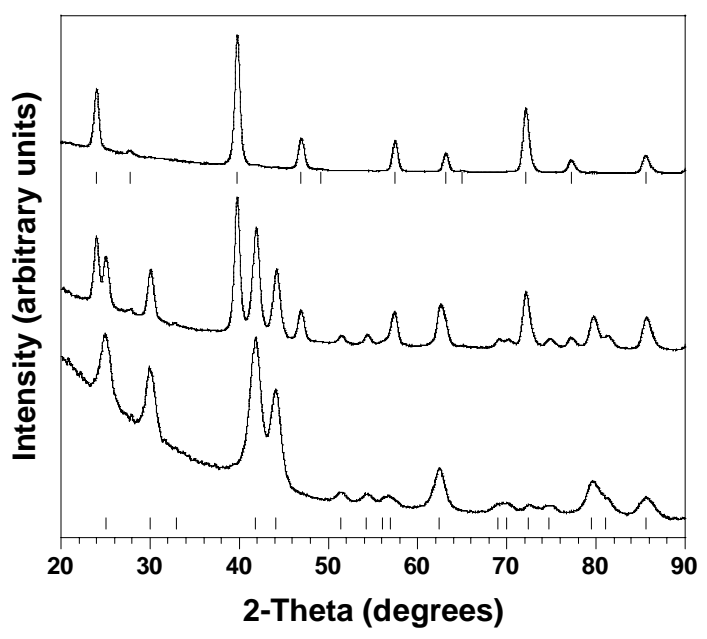

Figure S1. Powder XRD data for an aliquot (middle) taken during the conversion of nanocrystalline PtSn (bottom) to $\mathrm{PtSn}_{2}$ (top). The intermediate shows the presence of both PtSn and $\mathrm{PtSn}_{2}$ prior to complete conversion to $\mathrm{PtSn}_{2}$. 


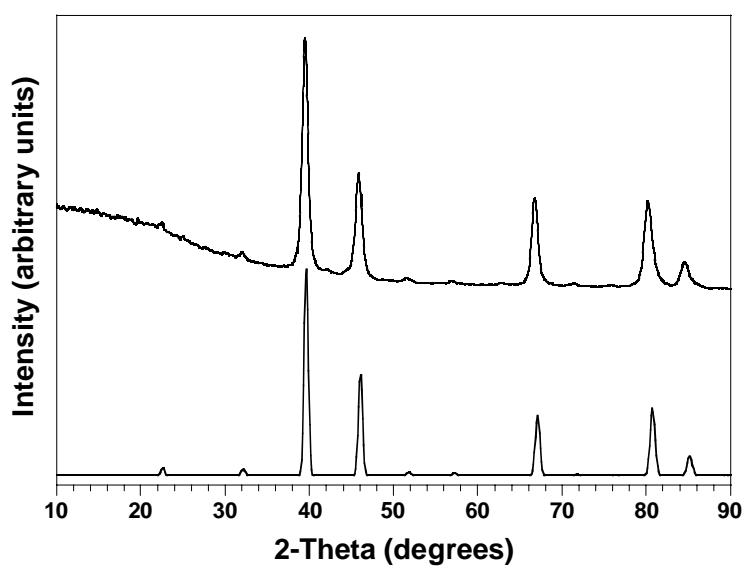

Figure S2. Experimental (top; annealed at $600{ }^{\circ} \mathrm{C}$, same as shown in Figure 2b) and simulated (bottom) XRD data for $\mathrm{Cu}_{3} \mathrm{Au}$-type $\mathrm{Pt}_{3} \mathrm{Sn}$.

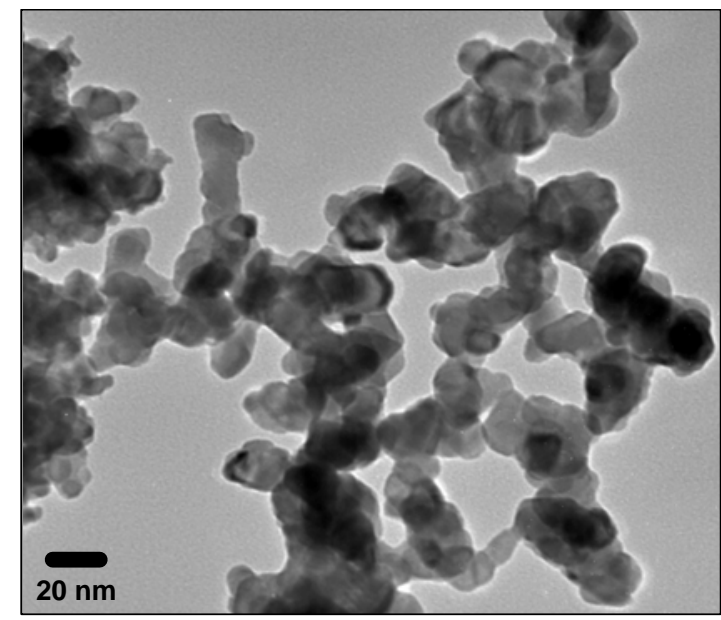

Figure S3. TEM micrograph of $\mathrm{PtSn}_{2}$ synthesized from the reaction of $\mathrm{PtSn}$ with $\mathrm{SnCl}_{2}(\mathrm{XRD}$ data shown in Figure 2a).
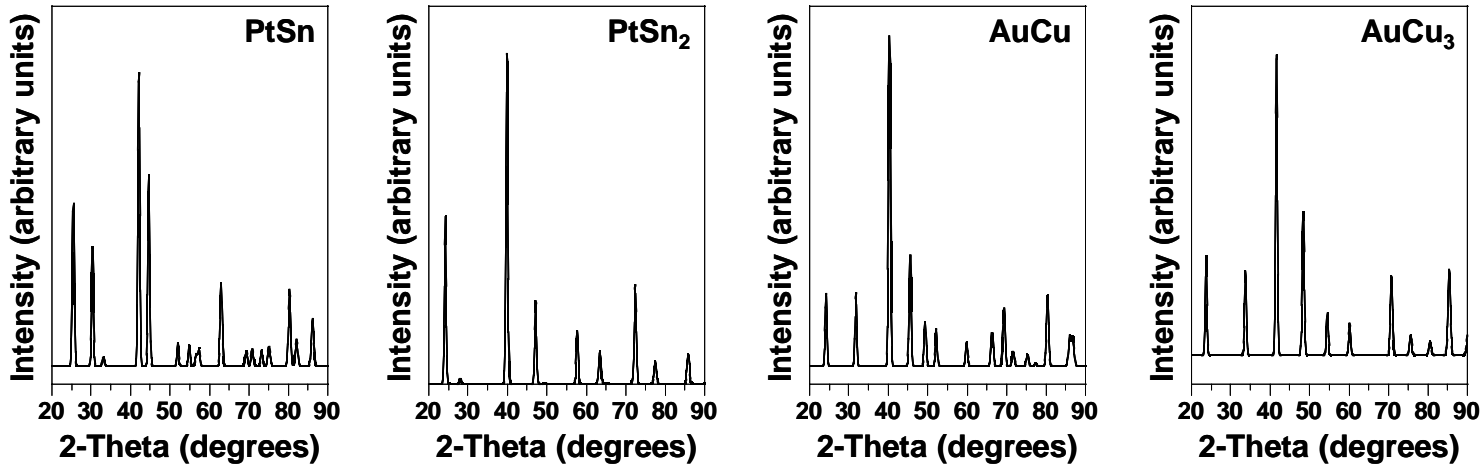

Figure S4. Simulated XRD data for $\mathrm{PtSn}, \mathrm{PtSn}_{2}, \mathrm{AuCu}$, and $\mathrm{AuCu}_{3}$. 